\title{
Independence Commitment dan Orientasi Etika pada Intensi Melakukan Whistleblowing dengan Moral Reasoning menjadi Variabel Moderasi
}

\author{
Oryza Daffa Alfi Syahr¹, David Adechandra Ashedica Pesudo²
}

1,2 Universitas Kristen Satya Wacana, Salatiga, Indonesia

\section{Keywords:}

Independence

Commitment;

Whistleblowing;

Moral Reasoning
Kata kunci:

Independence

Commitment;

Whistleblowing;

Moral Reasoning

\section{ABSTRACT}

Abstract: This study aims to determine the effect of ethical orientation and independence commitment on the intention to do whistleblowing with moral reasoning as a moderating variable in students. This study uses a quantitative descriptive approach. Methods of data collection using a questionnaire. The sampling technique used is purposive sampling in order to obtain a sample of 272 students as respondents in this study. The results of this study indicate that Independence commitment has a significant positive effect on the intention to do whistleblowing, with a low significant level, ethical orientation has no effect on the intention to do whistleblowing, and moral reosing cannot moderate the relationship between the two independent variables on the intention to do whistleblowing in students. active.

Abstrak: Penelitian ini bertujuan untuk mengetahui pengaruh orientasi etika dan independendence commitment terhadap intensi melakukan whistleblowing dengan moral reasoning sebagai variabel moderasi pada mahasiswa. Penelitian ini menggunakan pendekatan deskriptif kuantitatif. Metode pengumpulan data menggunakan kuesioner. Teknik sampel yang digunakan yaitu purposive sampling sehingga diperoleh 272 sampel mahasiswa sebagai responden dalam penelitian ini. Hasil dari penelitian ini menunjukkan bahwa Independence commitment memiliki pengaruh positif signifikan terhadap intensi melakukan whistleblowing, dengan tingkat signifikan yang rendah, orientasi etika tidak berpengaruh terhadap intensi melakukan whistleblowing, dan moral reosing tidak dapat memoderasi hubungan antara dua variabel bebas tersebut terhadap intensi melakukan whistleblowing pada mahasiswa aktif.

Alamat Korespondensi:

E-mail: 232017033@student.uksw.edu (Syahr)

\section{Pendahuluan}

Moral dideskripsikan sebagai karakteristik individu atau kelompok yang mendasari perilaku yang sesuai dengan norma yang ada (A. S. Lee \& Luo, 2016; T. T. Lee \& Osman, 2012). Secara etimologis moral berasal dari bahasa latin mores yang bermakna tata cara dalam berkehidupan, adat istiadat dan kebiasaan. Dengan kata lain (mores) moral adalah pedoman tentang sikap dan perilaku manusia yang baik dan benar (Haghighat, 2016; Park et al., 2018). Kematangan moral mengacu pada tingkat pertumbuhan atau kemampuan seseorang untuk membedakan yang benar dari yang salah, untuk mengembangkan kerangka nilai-nilai etis, dan belajar untuk bertindak secara moral (Haghighat, 2016). Semakin maraknya kasus kecurangan akademik yang terjadi di dalam dunia pendidikan, terbukti dari data yang ada dalam website Survei Fraud Indonesia pada tahun 2016, Association of Certified Fraud Examiners (ACFE) menunjukkan bahwa dalam setiap tahun terdapat 5\% rerata pendapatan suatu organisasi terdapat dari fraud. Data dari Report to The Nations (2018) menunjukkan bahwa terdapat 97 kasus fraud akademik yang terjadi di 125 negara di seluruh dunia. Kerugian yang diakibatkan oleh fraud juga perlu diperhatikan.

$\begin{array}{ll}\text { History: } & \\ \text { Received } & \text { : } 05 \text { April } 2021 \\ \text { Revised } & \text { : 06 April } 2021 \\ \text { Accepted } & : \text { 10 Juni } 2021 \\ \text { Published } & \text { : 25 Juli } 2021\end{array}$

Publisher: Undiksha Press

Licensed: This work is licensed under a Creative Commons Attribution 3.0 License (c) (i) (2) 
Jumlah kasus fraud akademik yang ada tidak sebesar korupsi maupun kecurangan laporan keuangan, tetapi fraud akademik dapat menyebabkan rata-rata kerugian hingga $\$ 68.000$, data tersebut menyebutkan bahwa kerugian yang dialami oleh Industri Pendidikan berada di urutan keenam dengan presentase sebesar 3,1\%, dengan jumlah itu maka fraud yang terjadi pada industri akademik juga menjadi masalah yang tidak dapat disepelekan. Lingkungan pendidikan merupakan tempat untuk para siswa dan mahasiswanya dimana mereka akan belajar untuk mempersiapkan diri masuk ke dunia profesional. Siswa dan mahasiswa tidak hanya memerlukan nilai tetapi juga membutuhkan sikap yang baik untuk maju ke dunia profesional. Hal ini membuktikan bahwa lingkungan pendidikan merupakan tempat yang harus dibangun dengan baik untuk membuat lulusan yang baik. Salah satu cara untuk mencegah kecurangan akademik adalah dengan melakukan whistleblowing. Whistleblowing adalah tindakan yang dilakukan individu atau sekelompok orang untuk mengungkap, melaporkan kecurangan kepada pihak lain (Dian \& Hidayati, 2019).

Akuntan menganggap bahwa independensi adalah yang utama dari atribut profesi, dan memegang teguh bahwa peraturan haruslah ditaati dan ditegakkan dalam lingkup akuntan publik (Safitri dan Dwita, 2019). Keterkaitan independensi seorang auditor dan diketahui bahwa aspek regulasi sangatlah penting untuk ditaati guna mendapatkan kepercayaan orang ketiga (Tang et al., 2017). Safitri dan Dwita (2019), mengatakan bahwa akuntan dengan Independence Commitment yang kuat untuk profesi mereka akan cenderung patuh pada peraturan dan menjunjung tinggi kewajiban bermoral dalam perilaku yang etis dan menjadi Whistleblower (Safitri \& Sany Dwita, 2019)(Dwitantra, 2015). Dalam kasus ini jika seorang mahasiswa memiliki komitmen dan dapat bersikap independen dalam melaksanakan kegiatan perkuliahan akan semakin mudah untuk melakukan Whistleblowing. Tujuan utama dari perilaku profesional yang berkaitan erat dengan moral dan nilai-nilai yang berlaku disebut orientasi etika. Orientasi dalam individu dipengaruhi oleh dua ciriciri utama yaitu idealisme dan relativisme (Purwati, 2017). Penelitian Mascarenhas (2019) menunjukkan bahwa orientasi etika dengan tingkat individualisme yang tinggi cenderung untuk mengungkap tindakan kecurangan yaitu dengan melakukan whistleblowing. Jika seorang mahasiswa memiliki persepsi yang positif mengenai etika yang di dalamnya terdapat nilai-nilai kejujuran dan keadilan maka intensi untuk melakukan whistleblowing akan semakin tinggi karena semakin jujur seorang individu maka akan semakin baik sehingga dia tidak akan tinggal diam jika melihat tindakan yang melanggar aturan.

Selain orientasi etika kematangan dalam bermoral juga menjadi salah satu faktor dalam melakukan tindakan pelaporan kecurangan (Dimitriou \& Schwepker, 2019). Sikap rasionalisasi ini yang menjadi faktor penting individu melakukan whistleblowing. Karena menurut Barrainkua \& Pike (2018) dengan memiliki kematangan dalam bermoral, individu tersebut merasa semua yang terjadi harus sesuai dengan norma dan peraturan yang berlaku dan berfikir bahwa hal yang dilakukan baik seperti tindakan pelaporan fraud tersebut. Dalam mengatasi masalah ini perlu adanya moral reasoning yang kuat pada setiap individu, guna menguatkan seseorang jika ingin melakukan pelaporan tindakan kecurangan. Penelitian ini bertujuan untuk menganalisis pengaruh Independence Commitment dan Orientasi Etika pada Intensi Melakukan Whistleblowing dengan Moral Reasoning menjadi Variabel Moderasi pada Fakultas Ekonomika dan Bisnis Universitas Kristen Satya Wacana.

\section{Metode}

Jenis penelitian ini menggunakan penelitian kualitatif. Populasi dalam penelitian adalah mahasiswa S1 Akuntansi Fakultas Ekonomika dan Bisnis Universitas Satya Wacana. Sampel penelitian dipilih menggunakan purposive sampling. Pengambilan sampel ini menggunakan kriteria mahasiswa yang sedang atau sudah mengambil mata kuliah pengauditan dan dianggap paham jika dihadapkan dengan kondisi dimana ditemukannya fraud academic dalam proses belajar mengajar. Sampel yang diambil untuk penelitian ini adalah mahasiswa aktif S1 Akuntansi FEB UKSW angkatan 2018 sampai 2016. Pemilihan sampel di dalam penelitian ini menggunakan rumus Slovin. Berdasarkan jumlah populasi yang telah didapat dari Bagian Admisi dan Registrasi (BARA) Universitas Kristen Satya Wacana (UKSW), terdapat 842 mahasiswa akuntansi aktif di FEB UKSW per 6 Juli 2020, dengan taraf 
signifikan yang diterapkan adalah 5\%, yang berarti bahwa peneliti yakin bahwa $95 \%$ hasil penelitian ini benar dan akan ada kemungkinan kesalahan yang akan terjadi sebesar $5 \%$. Sehingga diperoleh jumlah 272 responden.

Metode pengumpulan data menggunakan data primer yang didapat dengan cara penyebaran kuisioner kepada sampel yang sudah ditentukan. Penelitian ini dilakukan di kelas dengan mahasiswa akuntansi yang sedang menempuh mata kuliah pengauditan sebagai subjek eksperimen. Mahasiswa yang mengambil mata kuliah pengauditan dianggap sudah memahami mata kuliah pengauditan dan dianggap sudah paham apa yang dimaksud whistleblowing. Data yang diperoleh dari laporan responden secara individu yang berupa sikap, opini, pengalaman responden melalui kuisioner yang peneliti bagikan. Kuesioner dibagikan disesuaikan dengan jadwal mata kuliah responden. Tujuanya adalah agar tercapainya tingkat pengembalian kuesioner secara keseluruhan oleh partisipan. Pembagian kuesioner dilakukan di dalam kelas dengan memanfaatkan waktu luang setelah jam kuliah partisipan. Kuesioner yang digunakan pada penelitian ini berisikan pertanyaan yang diajukan oleh peneliti dan akan dijawab oleh responden, dengan menggunakan skala Likert ganjil (5 tingkat). Menurut Pranatawijaya, Widiatry, Priskila, \& Putra, (2019) Skala Likert adalah skala yang digunakan untuk mengukur persepsi, sikap ,opini atau pendapat seseorang atau kelompok mengenai sebuah peristiwa atau fenomena sosial. Penelitian ini menggunakan moderated regression analysis, untuk pengujian hipotesisnya. Analisis data berupa statistik deskriptif, pengujian validitas dan reliabilitas, pengujian asumsi klasik dan pengujian Hipotesis menggunakan persamaan regresi.

\section{Hasil dan Pembahasan}

\section{Hasil Penelitian}

Penelitian ini dilakukan dengan menyebarkan kuesioner via e-mail kepada mahasiswa aktif S1 Program Studi Akuntansi di Fakultas Ekonomika dan Bisnis Universitas Kristen Satya Wacana. Hasil perhitungan menunjukkan bahwa jumlah kuesioner yang dapat diolah pada penelitian ini adalah 283 buah. Hal ini dapat terjadi karena terdapat 8 kuesioner yang tidak dapat digunakan dalam penelitian ini. 8 kuesioner yang tidak dapat digunakan atau tidak dapat diolah dikarenakan pengisian jawaban pertanyaan yang tidak lengkap.

Tabel 1. Statistik Deskriptif

\begin{tabular}{|c|c|c|c|c|c|}
\hline & $\mathbf{N}$ & Minimum & Maximum & Mean & Std. Deviationj \\
\hline $\begin{array}{l}\text { Independence } \\
\text { Commitment }\end{array}$ & 287 & 15,00 & 40,00 & 32,4355 & 3,54519 \\
\hline $\begin{array}{l}\text { Orientasi } \\
\text { Etika }\end{array}$ & 287 & 23,00 & 45,00 & 36,7178 & 4,10957 \\
\hline $\begin{array}{l}\text { Intensi } \\
\text { Melakukan } \\
\text { Whistleblowing }\end{array}$ & 287 & 10 & 35,00 & 25,7282 & 3,73829 \\
\hline $\begin{array}{l}\text { Moral } \\
\text { Reasoning }\end{array}$ & 287 & 10 & 40,00 & 23,0244 & 4,46620 \\
\hline
\end{tabular}

Berdasarkan hasil perhitungan pada tabel 3, dapat diketahui bahwa terdapat 287 sampel yang digunakan pada penelitian ini. Dimana pada variabel independence commitment, memiliki nilai terendah sebesar 15 , nilai tertinggi sebesar 40 , rata-rata sebesar 32,43 , dan standar deviasi sebesar 3,56 . Lalu pada variabel orientasi etika memiliki nilai terendah sebesar 23 , nilai tertinggi sebesar 45 , rata-rata sebesar 36,71 , dan standar deviasi sebesar 4,10. Variabel intensi melakukan whistleblowing memiliki nilai terendah sebesar 10 , nilai tertinggi sebesar 35 , rata-rata sebesar 25,72 , dan standar deviasi sebesar 3,73 dan variabel moral reasoning memiliki nilai terendah sebesar 10 , nilai tertinggi sebesar 40, rata-rata sebesar 23,02 dan standar deviasi sebesar 4,46. Data ini menunjukkan bahwa penelitian ini memiliki data kualitas yang baik dengan nilai rata-rata yang lebih besar dari nilai 
standar devasi. 32,43\% responden percaya bahwa independence commitment berpengaruh dalam meningkatkan intensi melakukan whistleblowing. $36,71 \%$ responden percaya bahwa orientasi etika berpengaruh dalam dalam meningkatkan intensi melakukan whistleblowing. 23,02\% responden percaya bahwa moral reasoning berpengaruh dalam meningkatkan intensi melakukan whistleblowing.

Tabel 2. Hasil Uji Normalitas

\begin{tabular}{|c|c|c|}
\hline $\mathbf{N}$ & & $\begin{array}{l}\text { Unstandardized } \\
\text { Residual } \\
287\end{array}$ \\
\hline \multirow{3}{*}{ Normal Parameters } & Mean & 0,0000000 \\
\hline & Std. & 3,34036372 \\
\hline & Deviation & \\
\hline \multirow[t]{2}{*}{ Most Extreme } & Absolute & 0,046 \\
\hline & Posiitive & 0,031 \\
\hline Differences & Negative & $-0,046$ \\
\hline Test Statistic & & 0,046 \\
\hline Asymp. Sig. (2-tailed) & & 0,200 \\
\hline
\end{tabular}

Berdasarkan hasil perhitungan pada tabel uji normalitas, dapat dilihat bahwa nilai Asymp. Sig (2-tailed) menunjukkan nilai 0,200. Maka dapat disimpulkan bahwa data residual dalam penelitian ini berdistribusi normal, karena nilai Asymp. Sig (2-tailed) lebih besar dari 0,05.

Tabel 3. Hasil Uji Multikolinearitas

\begin{tabular}{cccc}
\hline Model & Tolerance & $\begin{array}{c}\text { Collinearity } \\
\text { Statistics } \\
\text { VIF }\end{array}$ \\
\hline X1 & $\begin{array}{c}\text { (Constant) } \\
\text { Independence } \\
\text { Commitmen } \\
\text { Orientasi Etika } \\
\text { Independence }\end{array}$ & 0,054 & 18,663 \\
X1X3 & $\begin{array}{c}\text { Commitmen terhadap } \\
\text { Moral Reasoning } \\
\text { Orientasi Etika } \\
\text { terhadap Moral } \\
\text { Reasoning }\end{array}$ & 0,051 & 19,693 \\
& 0,011 & 81,323 \\
\hline
\end{tabular}

Dari tabel di atas, dapat menunjukkan bahwa terjadi multikolinearitas antara variabel independen. Dapat dilihat bahwa tiap variabel memiliki nilai tolerance yang lebih kecil dari 0,1 dan nilai VIF yang lebih besar dari 10 dikarenakan penggunaan metode MRA yang menyebabkan adanya resiko pelanggaran multikolinearitas dikarenakan komponen variabel bebas yang ada merupakan hasil perkalian antara dua variabel bebas. 


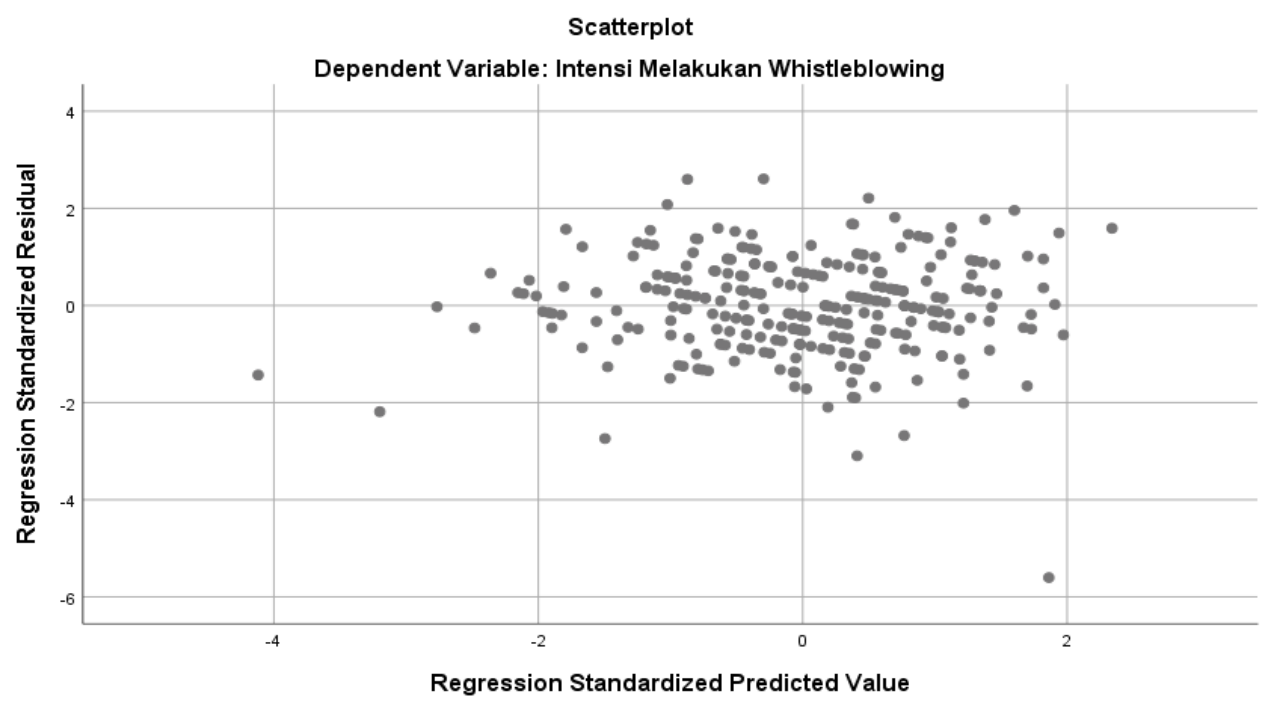

Gambar 1. Scatterplot

Dari gambar di atas, dapat disimpulkan bahwa tidak terdapat heteroskedastisitas pada penelitian ini. Hal tersebut ditunjukan oleh titik-titik yang tidak membentuk suatu pola tertentu. Lalu titik-titik tersebut tersebar di atas dan bawah angka 0 pada sumbu $X$ dan $Y$.

Tabel 4. Hasil Uji Autokorelasi

\begin{tabular}{cccccc}
\hline Model & $\mathbf{R}$ & R Square & $\begin{array}{c}\text { Adjusted } \mathbf{R} \\
\text { Square }\end{array}$ & $\begin{array}{c}\text { Std. Error } \\
\text { Of the } \\
\text { Estimated }\end{array}$ & $\begin{array}{c}\text { Durbin } \\
\text { Watson }\end{array}$ \\
\hline 1 & $0,449^{\mathrm{a}}$ & 0,202 & 0,190 & 3,36397 & 1,999 \\
\hline
\end{tabular}

Melalui tabel di atas dapat disimpulkan bahwa tidak terdapat autokorelasi pada penelitian ini. Hal ini dapat dilihat dengan nilai Durbin-Watson sebesar 1,999 lebih besar dari nilai dU 1,835 $(K=5, N=287)$. Dan nilai Durbin-Watson tersebut masih lebih rendah dari pada nilai 4-dU sebesar 2,165. Pada tabel diatas dapat dilihat bagaimana pengaruh antara Independence commitment dan Orientasi Etika terhadap intensi melakukan whistleblowing dengan moral reasoning sebagai variabel moderasi. Dari data tersebut dapat dilihat pada tabel B dan tabel t bahwa Independence commitment memiliki pengaruh positif signifikan terhadap intensi melakukan whistleblowing. Tidak hanya itu, pengaruh positif ini juga memiliki signifikansi sebesar 0,006 yang berarti berpengaruh (berada dibawah 0,05). Berarti dapat disimpulkan bahwa Independence commitment memiliki pengaruh positif yang signifikan terhadap intensi melakukan whistleblowing. Untuk pengaruh Orientasi Etika terhadap intensi melakukan whistleblowing, dapat dilihat dari tabel B dan tabel $\mathrm{t}$ bahwa Orientasi Etika memiliki pengaruh negatif terhadap intensi melakukan whistleblowing. Pengaruh negatif ini juga memiliki juga memiliki signifikansi sebesar 0,648 , yang berarti tidak signifikan (berada diatas 0,05). Dapat disimpulkan bahwa Orientasi Etika tidak berpengaruh terhadap intensi melakukan whistleblowing.

Penelitian ini menunjukkan bahwa Independence commitment memiliki pengaruh positif signifikan terhadap intensi melakukan whistleblowing, dengan tingkat signifikan yang rendah. Hal ini menunjukkan bahwa hipotesis pertama dapat diterima. Hal ini dapat terjadi karena beberapa aspek didalamnya seperti aspek individual, situasional dan lingkungan. Independence commitment dapat timbul pada diri masing-masing mahasiswa jika di dalam diri mahasiswa itu sendiri sudah memiliki sifat independensi yang tinggi dan tidak takut untuk mengambil resiko. Selain itu faktor lingkungan dan situasional juga dapat mempengaruhi kepribadian seorang mahasiswa untuk memiliki Independence commitment Pada penelitian ini, mahasiswa akuntansi yang menjadi 
responden menunjukkan hasil bahwa mahasiswa yang memiliki Independence commitment akan melakukan whistleblowing. Ini menunjukkan bahwa semakin tinggi Independence commitment yang dimiliki mahasiswa maka tingkat intensi melakukan whistleblowing akan semakin tinggi juga. Hal ini sejalan dengan penelitian yang telah dilakukan oleh (Safitri \& Dwita, 2019). Penelitian ini menyatakan bahwa orientasi etika tidak berpengaruh terhadap intensi melakukan whistleblowing, sehingga hipotesis kedua ditolak. Dapat dilihat dari uji T yang terdapat pada tabel 10 yang menujukkan tingkat signifikansi berada diatas 0,05 . Hasil penelitian ini tidak sejalan dengan penelitian Purwati (2017) yang menunjukkan bahwa orientasi etika memiliki pengaruh positif terhadap intensi melakukan whistleblowing.

Tabel 5. Hasil Uji T

\begin{tabular}{|c|c|c|c|c|c|c|}
\hline \multirow{3}{*}{\multicolumn{2}{|c|}{ Model }} & \multicolumn{3}{|c|}{ Coefficients $^{\mathrm{a}}$} & \multirow{3}{*}{$t$} & \multirow{3}{*}{ Sig. } \\
\hline & & \multicolumn{2}{|c|}{$\begin{array}{l}\text { Unstandardized } \\
\text { Coefficients }\end{array}$} & \multirow[t]{2}{*}{$\begin{array}{c}\text { Standardized } \\
\text { Coefficients Beta }\end{array}$} & & \\
\hline & & B & Std. Error & & & \\
\hline \multirow[t]{7}{*}{1} & (Constant) & 8,154 & 2,167 & & 3,762 & 0,000 \\
\hline & Independence & 0,675 & 0,242 & 0,640 & 2,786 & \\
\hline & commitment & & & & & 0,006 \\
\hline & Orientasi Etika & $-0,098$ & 0,215 & $-0,108$ & $-0,457$ & 0,648 \\
\hline & Independence & $-0,015$ & 0,011 & & $-1,424$ & 0,155 \\
\hline & $\begin{array}{l}\text { commitment*Moral } \\
\text { Reasoning }\end{array}$ & & & $-0,683$ & & \\
\hline & $\begin{array}{l}\text { Orientasi Etika*Moral } \\
\text { Reasoning }\end{array}$ & 0,012 & 0,009 & 0,677 & 1,352 & 0,178 \\
\hline
\end{tabular}

Orientasi etika dapat berpengaruh positif terhadap intensi melakukan whistleblowing ketika etika yang ada dalam lingkungan pendidikan mendukung untuk melaporkan kecurangan yang ada sedangkan mahasiswa juga tidak ingin mengambil risiko untuk melakukan whistleblowing karena risiko yang diterima ketika melakukan whistleblowing dapat sangat merugikan mahasiswa, seperti mendapat perlakuan buruk dari teman-temannya. Hal tersebut memperkecil kemungkinan adanya peluang untuk melakukan melaporkan kecurangan sehingga mahasiswa enggan untuk melakukan whistleblowing menurut Yulianto (2015). Penelitian ini menyatakan bahwa moral reosing tidak dapat memoderasi hubungan antara dua variabel bebas tersebut terhadap intensi melakukan whistleblowing, sehingga hipotesis ketiga dan keempat ditolak. Dapat dilihat dari uji T yang terdapat pada tabel 10 yang menujukkan tingkat signifikansi berada diatas 0,05. Model moderating yang ditentukan sebagai pembeda pada penelitian ini yaitu moral reasoning tidak dapat memoderasi hubungan antara variabel bebas dan variabel terikat disebabkan karena tinjauan teoritis yang kurang tepat sehingga analisis dengan moderating mengkonfirmasi bahwa teori tersebut tidak cocok dengan model empiris. Hal ini sejalan dengan penelitian yang telah dilakukan oleh Wendy (2020).

\section{Simpulan}

Independence commitment berpengaruh positif signifikan terhadap intensi melakukan whistleblowing. Sedangkan orientasi etika tidak berpengaruh terhadap intensi melakukan whistleblowing, dan Moral Reasoning terbukti tidak dapat memoderasi hubungan antara orientasi etika dan independence commitment terhadap intensi melakukan whistleblowing. Keterbatasan pada penelitian ini adalah variabel moderasi yang ditambahkan sebagai pembeda yaitu moral reasoning tidak dapat memoderasi hubungan antara variabel terikat dan variabel bebas yang ada. Keterbatasan 
yang lain adalah objek pada penelitian ini hanya ditujukan kepada beberapa mahasiswa saja yang dijadikan sampel hasil dari penelitian ini tidak dapat direalisasikan. Terdapat juga beberapa kuesioner yang tidak kembali dan tidak dapat diolah dikarenakan pengisiannya yang tidak lengkap. Saran untuk peneliti selanjutnya dapat mengganti variabel moral reasoning dengan variabel moderasi yang lain yang dapat meoderasi variabel yang, contohnya seperti sosialisasi antisipatif, serta dapat melakukan penelitian dengan menambahkan kerangka penelitian fraud pentagon, ataupun penelitian kedepan dapat menggunakan subjek penelitian lain selain mahasiswa.

\section{Daftar Pustaka}

Barrainkua, I., \& Espinosa-Pike, M. (2018). The influence of auditors' commitment to independence enforcement and firms' ethical culture on auditors' professional values and behaviour. Research on Professional Responsibility and Ethics in Accounting, 21, 17-52. https://doi.org/10.1108/S1574-076520180000021002.

Dimitriou, C. K., \& Schwepker, C. H. (2019). Enhancing the lodging experience through ethical leadership. International Journal of Contemporary Hospitality Management, 31(2), 669-690. https://doi.org/10.1108/IJCHM-10-2017-0636.

Dwitantra, P. (2015). Pengembangan Perangkat Pembelajaran Model Discovery \& Course Review Horay (Disco) Pada Pembelajaran Lagu Daerah Nusantara Kelas 5 Sekolah Dasar Berbasis Kurikulum 2013. Journal of Primary Education, 3(2). https://doi.org/https://doi.org/10.15294/jpe.v3i2.6966.

Faniati Dian Bakar, Nur Hidayati, dan M. A. (2019). Pengaruh Komitmen Profesional, Locus of Control dan Sosialisasi Antisipatif Mahasiswa terhadap Whistlebloing. E-Jra, 08(09), 1-13.

Haghighat, E. (2016). Cultural Dimensins and Moral Reasoning: a Comparative Study. 2, 23-31.

Lee, A. S., \& Luo, X. (2016). Perceived ethicality of moral choice: the impact of ethics codes, moral development and relativism. Nankai Business Review International, 2001-2012.

Lee, T. T., \& Osman, K. (2012). Interactive Multimedia Module in the Learning of Electrochemistry: Effects on Students' Understanding and Motivation. Procedia - Social and Behavioral Sciences, 46, 1323-1327. https://doi.org/10.1016/j.sbspro.2012.05.295.

Oswald A. J. Mascarenhas, S. J., \& Oswald A. J. Mascarenhas, S. J. (2019). The Ethics of Corporate Moral Reasoning, Moral Judgment, and Moral Justification. In Corporate Ethics for Turbulent Markets. https://doi.org/10.1108/978-1-78756-191-520191008.

Park, N., Kang, N., \& Oh, H. S. (2018). Examining intention of digital piracy: an integration of social norms and ethical ideologies. Journal of Information, Communication and Ethics in Society, 16(2), 157-172. https://doi.org/10.1108/JICES-11-2016-0043.

Pranatawijaya, V. H., Widiatry, W., Priskila, R., \& Putra, P. B. A. A. (2019). Penerapan Skala Likert dan Skala Dikotomi Pada Kuesioner Online. Jurnal Sains Dan Informatika, 5(2), 128. https://doi.org/10.34128/jsi.v5i2.185.

Purwati, A. A. dan. (2017). Pengaruh Orientasi Etika, Komitmen Profesional, dan Sosialisasi Antisipatif terhadap Intensi Melakukan Whistleblowing pada Kecurangan Akademik. Journal of Chemical Information and Modeling, 53(9), 1689-1699. https://doi.org/10.1017/СBO9781107415324.004.

Safitri, Y. E., \& Sany Dwita. (2019). Pengaruh Independence Commitment Terhadap Niat Melakukan Whistleblowing Dengan Group Cohesion Sebagai Variabel Moderasi: Sebuah Studi Eksperimen. Jurnal Eksplorasi Akuntansi Vol. 1, No 4, Seri A, November 2019, Hal 1617-1632, 53(9), 1689-1699. https://doi.org/10.1017/CBO9781107415324.004.

Tang, F., Ruan, L., \& Yang, L. (2017). Does regulator designation of auditors improve independence?: The moderating effects of litigation risk. Managerial Auditing Journal, 32(1), 2-18. https://doi.org/10.1108/MAJ-03-2016-1334.

Wendy, S. (2020). Universitas Bung Hatta Padang. IV(3), 1-11.

Yulianto. (2015). Pengaruh Orientasi Etika, Komitmen Profesional, dan Sensitifitas Etis Terhadap Whistleblowing. 